\title{
Mobile Government Adoption Model Based on Combining GAM and UTAUT to Explain Factors According to Adoption of Mobile Government Services
}

https://doi.org/10.3991/ijim.v14i03.11264

\author{
Mohammed Amin Almaiah ( $\bowtie)$ \\ King Faisal University, Al- Ahsa Saudi Arabia \\ malmaiah@kfu.edu.sa \\ Ahmad Al-Khasawneh \\ Hashemite University of Jordan, Zarqa, Jordan \\ Ahmad Althunibat \\ Al-Zaytoonah University of Jordan, Amman, Jordan \\ Saleh Khawatreh \\ Al Ahliyya Amman University, Amman, Jordan
}

\begin{abstract}
This research examines the mobile-government services adoption, by combining both UTAUT and GAM models with adding new constructs for explaining the key factors that affect on adoption of mobile-government services. As a result, the study identified the critical factors that influence users' to adopt the system, and developed an integrated model as a powerful tool that assists in the adoption process of mobilegovernment applications. The novelty of this research will be an added value to the body of knowledge and its implications will be vital for researchers and decision/policy makers who are willing to make a change.
\end{abstract}

Keywords-Mobile-government services, Adoption, GAM model, UTAUT model.

\section{Introduction}

Many governments have recently made a significant transition to use mobile technologies and applications and wireless networks to provide their services and conduct their government transactions and services; this transition has created what is known as mobile government. These mobile government applications can support quick access to integrated data, information and location-based services (based on anytime, anyplace and anyhow); creating pioneering opportunities for innovative public services management and delivery [1]. Mobile government is one of those recent technologies that came to enhance the performance of public services administration and management as one of the key domains for societies and nations. This innovative and modern trend enables 
providing governmental services for citizens, businesses, employees and other governmental agents [2];[3].

In fact, through such mobile-government application, governments are able to offer a wide range of services that can be acquired using different types of wireless devices, during unlimited time intervals, and from different locations. It has been reported that, while e-government initiatives were a crucial step taken by many governments, provision of services through mobile technologies is then now inevitable [4]. Yet, similar to any other new technology or digital innovation, mobile government implementation remain to face some critical technical, as well as non-technical challenges, particularly adoption and acceptance [4];[5].

Several researchers have recommended for richer modelling and theorizing of acceptance and adoption in the area of new mobile technologies and systems related research. However, few efforts have actually been done in studying the adoption and acceptance of new mobile technologies and applications for governments, banking and others [6];[7];[8];[9]. Also, it has been frequently recommended for more extensions of some models and theories, and advised to apply or use such models and theories to the new areas of ICT technologies and other evolving domains such as smart government or mobile-government [10];[11];[12].

Therefore, this study attempts to fill this gap by integrating The Unified Theory of Acceptance and Use of Technology (UTAUT) with E-Government Adoption Model (GAM) in order to investigate the main antecedents of mobile government services adoption.

\section{Theoretical Background}

This section will provide analysis of several widely developed, validated and used user-centred models and theories with focus on factors affecting the adoption, acceptance, use and success in the area of Information and Communication Technology (ICT) oriented products and services, including mobile-government. This brief theoretical background will be the foundation for the description and development of the research framework or model and hypotheses for this research. Following the introduction, detailed review of the different user-centred models and theories regarding the adoption, acceptance, use and success of technologies, particularly the mobile-government, will be provided.

\subsection{Mobile government}

Mobile government offers many chances. It offers more availability and accessibility since individuals have the ability to access the government information on the basis of anytime and anywhere. In general, mobile phones are always on as well as they are always carried around. Moreover, it permits the government to quickly deliver modified content to the end-users. It also permits governments to arrive at a superior number of individuals, practically the individuals who live in the rural areas as well as do not possess a great experience with the computers [13]. The advantages can be illustrated from 
the view point of citizens and employees [14]. From the viewpoint of citizens, mobilegovernment contributes to saving money, effort and time through having the ability to access the government information and services on the basis of anywhere and anytime [15]. Mobile-government provides several benefits including the benefits represented in enhancing the delivery of government services and information; consequently, the individuals have the ability to get instant access on the basis of any time and any place. As for the employees, mobile-government offers a flawless environment for them in order to meet and communicate with no need to plug into the interface of network. Furthermore, in order to access information at any time and any place for the purpose of making faster and better decisions. Furthermore, mobile-government develops effectiveness and efficiency of government employees, since they have the ability to access the needed information instantly as well as update records on the spot. Furthermore, mobile-government has the ability to open up extra channels for the participation of citizens [16].

However, with the advent of smartphones and mobile applications and technologies, the Jordanian government started shifting into the implementation of mobile-government, regardless of making services transition from e-government to mobile-government or introducing services directly via mobile-government [17]. However, the uptake in the area of mobile-government as general remains below the potential target and the services have not reached the expected adoption levels [18].

\subsection{Related studies on e-government and mobile-government adoption}

The success of any system, including mobile information system, is determined by how many people use the system [19];[20]. In mobile-government services, acceptance of the service is vital in achieving success [17]. Many studies have identified a number of factors that determine the adoption of e-government services. For example, Alenezi et al., [21] used Kuwait as a case study for a qualitative investigation. The results indicated that three factors (user satisfaction, institutional values and information quality) were observed to achieve better e-government benefits. Alshehri, Drew and Al Ghamdi [22] carried out a similar investigation in Saudi Arabia in an empirical study that used the UTAUT model. The researchers found that facilitating conditions, social influence, performance expectancy are the main influential factors for motivating the citizens in Saudi Arabia to adopt e-government services. Lin et al. [23] used an adapted TAM model in the Gambia to investigate constructs like attitude, information system quality and information quality. It appears that almost all constructs support intention except for perceived usefulness. The most important construct related to intention was attitude, and the most important factors related to perceived usefulness were perceived ease of use and quality of information. A recent research carried out by the Kurfalı, Arifoğlu, and Tokdemir [24] used the UTAUT model to identify what determines use of e-government services in Turkey. The most influential factors were facilitating conditions, social influence, performance expectancy, and overall trust of the Internet. Lallmahomed et al. [25] used UTAUT2 with GAM to investigate the factors that affect the citizens adoption of e-government services in Mauritius. The results indicated that per- 
formance expectancy and perceived value are the main factors that predict the e-government adoption. In addition, they found that resistance to change and self-efficacy have a negative effect on intention to adopt e-government adoption. Akhtar Shareef, Kumar, Kumar, \& Dwivedi [26] proposed GAM model to identify the main factors that lead to enhance the acceptance of e-government system in Canada. They found that Perceived Awareness, Availability of Resources, Self Efficacy, Perceived Ability to Use, Perceived Information Quality, Perceived Trust, Perceived Functional Benefit, Perceived Image, Perceived Security and Perceived Privacy are the critical factors for e-government adoption.

Although, there are many studies conducted that determine the adoption of e-government, little consideration has been paid to explore the main factors that influence the adoption of mobile-government services. For instance, Liu et al. [27] conducted an empirical study in China to explore the factors that affect the adoption of mobile-government. They indicated that intention to use of mobile-government influenced positively by perceived ease of use, social influence, near-term usefulness and long-term usefulness. In the same way, Wang [28] investigated the post-adoption factors of mobilegovernment in China. They revealed that the significant factors that lead to continuous use of mobile-government services after implementation are trust and user satisfaction and also it has a significant impact on perceived value. Almarashdeh and Alsmadi [14] proposed a model by integrating the TAM and UTAUT to investigate about the factors that encourage the use of mobile-government services among citizens. The empirical results indicated that perceived trust, cost of service, perceived ease of use, social influence and perceived usefulness have significant impact on the continuous use of mobile-government services among citizens. Ahmad and Khalid [29] tested empirically the TAM model by adding 4 external factors (perceived usefulness, social influence, trust and cost) to investigate citizens' intention to use mobile-government services in UAE. The study found that social influence and trust are positively impacted on citizens' intention to use mobile-government services. In the same way, Sharma, Al-Badi, Rana, and Al-Azizi [4] in his study found that performance expectancy and trust have significant determining acceptance of m-government services in Oman.

Table 1. Prior studies on e-government and mobile-government adoption

\begin{tabular}{|l|l|l|l|}
\hline \multicolumn{1}{|c|}{ Literature } & Context area & \multicolumn{1}{c|}{ Model Used } & $\begin{array}{c}\text { Factors affecting e- and m-gov- } \\
\text { ernment adoption }\end{array}$ \\
\hline $\begin{array}{l}\text { Alenezi et al., } \\
\text { [21] }\end{array}$ & E-government & Delone and Mclean model & $\begin{array}{l}\text { User satisfaction, institutional val- } \\
\text { ues and information quality }\end{array}$ \\
\hline $\begin{array}{l}\text { Drew and Al } \\
\text { Ghamdi [22] }\end{array}$ & E-government & UTAUT model & $\begin{array}{l}\text { Facilitating conditions, social influ- } \\
\text { ence, and performance expectancy }\end{array}$ \\
\hline Lin et al. [23] & E-government & TAM model & $\begin{array}{l}\text { Attitude, system quality, infor- } \\
\text { mation quality, perceived useful- } \\
\text { ness and perceived ease of use }\end{array}$ \\
\hline $\begin{array}{l}\text { Kurfal1, Ari- } \\
\text { foğlu, and } \\
\text { Tokdemir [24] }\end{array}$ & E-government & UTAUT model & $\begin{array}{l}\text { Facilitating conditions, social influ- } \\
\text { ence, performance expectancy and } \\
\text { trust. }\end{array}$ \\
\hline $\begin{array}{l}\text { Lallmahomed } \\
\text { et al. [25] }\end{array}$ & E-government & UTAUT2 model & $\begin{array}{l}\text { Performance expectancy, perceived } \\
\text { value, resistance to change and } \\
\text { self-efficacy. }\end{array}$ \\
\hline
\end{tabular}




\begin{tabular}{|l|l|l|l|}
\hline $\begin{array}{l}\text { Akhtar } \\
\text { Shareef, Ku- } \\
\text { mar, Kumar, } \\
\text { and Dwivedi } \\
\text { [26] }\end{array}$ & E-government & GAM model & $\begin{array}{l}\text { Perceived Awareness, Availability } \\
\text { of Resources, Self Efficacy, Per- } \\
\text { ceived Ability to Use, Perceived } \\
\text { Information Quality, Perceived } \\
\text { Trust, Perceived Functional Bene- } \\
\text { fit, Perceived Image, Perceived Se- } \\
\text { curity and Perceived Privacy }\end{array}$ \\
\hline Liu et al. [27] & $\begin{array}{l}\text { Mobile-govern- } \\
\text { ment }\end{array}$ & TAM model & $\begin{array}{l}\text { Perceived ease of use, social influ- } \\
\text { ence, near-term usefulness and } \\
\text { long-term usefulness }\end{array}$ \\
\hline $\begin{array}{l}\text { Wang [28] } \\
\text { Almarashdeh } \\
\text { and Alsmadi }\end{array}$ & $\begin{array}{l}\text { Mobile-govern- } \\
\text { ment }\end{array}$ & - & $\begin{array}{l}\text { Trust, user satisfaction, perceived } \\
\text { value }\end{array}$ \\
\hline $\begin{array}{l}\text { Ahmad and } \\
\text { Khalid [29] }\end{array}$ & $\begin{array}{l}\text { Mobile-govern- } \\
\text { ment }\end{array}$ & TAM model & $\begin{array}{l}\text { Perceived trust, cost of service, } \\
\text { perceived ease of use, social influ- } \\
\text { ence and perceived usefulness }\end{array}$ \\
\hline $\begin{array}{l}\text { Sharma, Al- } \\
\text { Badi, Rana, } \\
\text { and Al-Azizi } \\
\text { [4] }\end{array}$ & $\begin{array}{l}\text { Mobile-govern- } \\
\text { ment }\end{array}$ & TAM and UTAUT & $\begin{array}{l}\text { Perceived usefulness, social influ- } \\
\text { ence, trust and cost }\end{array}$ \\
\hline
\end{tabular}

Based on above review in Table 1, despite many studies have been conducted by several researchers in the domain of mobile-government adoption, the existing literature review findings reveal that most of these studies were mainly focused on UTAUT and TAM models to investigate the mobile-government services adoption by examining some factors as shown in Table 1. In fact, the existing literature on mobile-government has failed to provide a comprehensive model of mobile-government adoption. Therefore, this study is attempting to identify all of the main factors of mobile-government services adoption from our detailed literature review in conjunction with the insight from different models related to IS/IT adoption, acceptance and usage.

\subsection{Mobile-government adoption and IS/IT adoption models}

This section highlights and examines different theories and models relevant to a new technology adoption, and the need for researchers to adopt the one which meets the research objectives. For this research, the main objective is to identify the main factors influencing mobile-government services adoption in Jordan and hence investigate the citizens' use of mobile-government services. This investigation will be conducted through a conceptual model that maps the proposed factors influencing mobile-government adoption in Jordan from a citizen's perspective.

According to the literature review in Table 1, many theories and models have been developed by several scholars and researchers to examine the users' acceptance of new technologies and their intention to use such technologies. Every model and theory were adopted, modified and validated by other researchers in order to bring insight and predict technology acceptance and usage [30]. Furthermore, in the last two or three decades, according to some literature reviews, some models and theories were extended to other theories and models to predict technology acceptance and adoption. For example: TAM was developed by Davis [31], and was extended to TAM2 by [30], and TRA was developed by Ajzen and Fishbein [32], and was extended to TBP by [33]. 
Many researchers conducted a comparative analysis between the most suitable models in order to choose the most relevant models and theories with sound theoretical and empirical bases that meets the research purpose, and then ignored other models [34];[35];[36]. Based on this concept, this study conducted a review among the models which are the most robust and significant in describing IT/IS adoption behaviour. Each one will be explained in detail in the following sections, followed by the main justification for using a specific model for this study.

\subsection{Justifying UTAUT as theoretical foundation in this study}

This section will present a justification for the suggestion of UTAUT as a usable model for technology adoption, appropriate to the mobile-government services, and hence its application to this study. The critique in this section is based upon existing analysis of the literature about the suitability of UTAUT as the selected model for this study. To this end, the researcher compared UTAUT to other most important models in the field of adoption technologies.

According to the literature, UTAUT has the upper explanatory power compared to other relevant models and theories in IS/IT adoption context. According to Al-Mamary et al. [37], the UTAUT is the most popular model in the field of technology adoption and focus on the technology factors of the successful implementation of information systems. The same thought is reported in several studies. Surendran [38] for example, stated that UTAUT is one of the most popular research models to predict use and acceptance of information systems and technology by users based on certain factors that can be used with it.

According to many studies, UTAUT was proved to be a valid model for explaining and predicting citizens' adoption behaviour regarding the use of e-Services in many countries [39]. In addition, UTAUT has received a high level of attention through literature compared to other models such as TRA, TAM, and TAM2 [40]. UTAUT is still considered more efficient and it has higher explanatory power as compared to other models [39]. Most researchers used UTAUT to test new technologies based on the two beliefs (performance expectancy and effort expectancy) as primary for technology acceptance behavior [31].

Finally, in a meta-analysis review study conducted by Walldén, Mäkinen, \& Raisamo, [41], 69 published studies were reviewed and concluded that the UTAUT is a valid and robust model based on substantial empirical evidence in the studies. Therefore, the researcher selected UTAUT to develop a conceptual model for this study in order to achieve a solid base to explain why users accept or reject mobile-government services. Based on that, the UTAUT forms the theoretical foundation of the proposed research model for this study.

\subsection{E-Government Adoption Model (GAM)}

GAM model developed by Shareef, Kumar, Kumar, and Dwivedi [42] is mainly focused for the e-government adoption context. This model was proposed for investigating the critical factors that influence the adoption of e-government in different level of 
service maturity. GAM is a comprehensive model that consists of thirteen constructs namely: Perceived Trust, Perceived Information Quality, Perceived Awareness, , Availability of Resources, Perceived Ability to Use, Perceived Compatibility, Self Efficacy, Perceived Image, Perceived Service Response, Perceived Security and Perceived Privacy, Perceived Uncertainty and Perceived Functional Benefit.

Several researches in the literature have applied the GAM model to investigate the adoption of e-government. For example, Lallmahomed et al. [25] used UTAUT2 with GAM to identify the factors that influence the citizens adoption of e-government services. They indicated that the GAM model is relatively new to the IS adoption field, and it is currently being used to investigate e-government adoption [25]. Akhtar Shareef, Kumar, Kumar, \& Dwivedi [26] proposed GAM model to identify the main factors that could lead to improve the adoption of e-government system in Canada. They found that Perceived Awareness, Availability of Resources, Self-Efficacy, Perceived Ability to Use, Perceived Information Quality, Perceived Trust, Perceived Functional Benefit, Perceived Image, Perceived Security and Perceived Privacy are the critical factors for e-government adoption. Shareef, Baabdullah, Dutta, Kumar, and Dwivedi [43] conducted a study to explore the consumers' behavioral intentions to adopt mobile banking in Bangladesh by extending the GAM model. They found that five variables (perceived trust, perceived ability to use, perceived functional benefit, perceived information quality and perceived awareness) have significant effect on the m-banking adoption.

According to Shareef et al. [42], GAM model has been and could be used in different studies, researches, and with different applications/settings such as e-banking, e-commerce, e-government and it could explain technology adoption from different perspectives like behavioral, technological, social, cultural, and organizational. Furthermore, GAM is a robust model and it has a comprehensive structure, which contains fourteen constructs to provide a good explanation for the adoption of e-government [42]. However, despite the importance of this model in determining the success factors for the egovernment adoption, none of existing studies so far have used the GAM model to investigate the adoption factors of mobile-government services. Therefore, the researcher used the GAM model as a theoretical foundation of the proposed research model for this research, but with some modifications to suit the context of this study.

\section{The Proposed Model: Mobile-Government Adoption Model (MGAM)}

Figure 1 presents the proposed research model used in this research to study the research topic related to mobile-government adoption by analysing different models and theories in the context of IT/IS. The proposed model is a road map for empirical data collection and analysis in this research, using it as the applicable theoretical background in examining the factors influencing the adoption of mobile-government services.

As aforementioned, in this study, the researcher reviewed previous studies about the main theories and models for the adoption of new technology, along with considering 
the main factors in order to propose an integrated model that maps the key factors influencing mobile-government services adoption. Based on above literature review, the researcher used the UTAUT and GAM model as a theoretical foundation of the proposed research model for this research, but with some modifications to suit the context of this study. Below, the proposed hypotheses in the proposed model was explained.

Perceived Compatibility (PCM): Perceived compatibility defined by Rogers [45], is the degree to which an IS/IT innovation is perceived as consistent with the needs and perceptions of potential users. Researchers e.g., [42] thought that users will adopt egovernment system when it is compatible with their needs and their online government services. In addition, based on many studies conducted in the literature, perceived compatibility is one of the key indicators that influence the use and adoption of IT/IS in different settings like e-learning system [44] e-government system [42]. Based on current discussion, we posit that:

H1: Perceived compatibility will have a significant effect on mobile-government adoption

Perceived Trust (PT): In relation to mobile-government studies, trust is "a user`s confidence in the mobile government system's ability to provide a reliable and efficient service" [28]. To earn users` trust, they must have confidence in the technology itself, and the means by which the technology reaches them [11]. In relation to mobile services, this means placing trust in both the internet and government department providing the service. The use of mobile and online services is affected by whether or not governments can implement services effectively and securely [46]. At first, citizens are often hesitant because of the unfamiliar risks associated with e-government services [17]. A lack of trust leads to increased resistance to use mobile services. The people that trust the government are inclined to use and share government services as long as they think it is safe and secure [47]. Thus, the following hypothesis is proposed:

H2: Perceived trust of the Internet will have a significant effect on trust of mobilegovernment services

H3: Perceived trust of the internet will have a significant effect on trust mobilegovernment services

H4: Perceived trust of the government will have a significant effect on mobile-government adoption

Self-Efficacy (SE): Self efficacy refers to the degree of users' technological capability to use, interact, and transact with mobile-government applications based on prior knowledge, experience, and skill as they perceive it is required to do so [48]. Several studies [25];[49], found that self-efficacy is one of the core elements in determining adoption of the e-government services. For example, Mensah and Mi [49] stated that self-efficacy factors has a positive influence on continues intention to use of e-government system. Almaiah and Naserddin [50] indicated that self-efficacy is one important factor that needs to be considered through "Jordan's Vision 2025". They outlined the "Jordan's Vision 2025" as the e-government Authority seeks to ensure that all Jordanian people use the mobile-government services and have full self-efficacy and skills to use the system with the end of 2025. According to Lallmahomed et al. [25], in order to increase the adoption of e-government services, it is important to ensure people have high self-efficacy in order meet the intended function, otherwise it's hard to achieve the 
objective if citizens show low self-efficacy. In addition, training programs can play a significant role in ensuring high self-efficacy for users, and for that reason the e-government should create some training programs for users to enhance their skilled human, and hence, become more likely to adopt e-government services. Thus, this research proposes:

H5: Self efficacy will have a significant effect on mobile-government adoption

Perceived Information Quality (PIQ): Sá, Rocha, and Cota, [51] noted that information quality is an important factor that needs to be considered and it is playing a vital role in success of e-government services. Shareef et al. [42] thought that better information quality will encourage users and citizens to adopt and use the e-government services. Perceived information quality factor refers to the quality, accuracy, and format, of information provided by the systems and applications. Perceived information quality is measured by a group of dimensions like accuracy, completeness, timeliness, relevance, and efficiency of information [34]. Practically, mobile-government system has many benefits to citizens because of the richness of government information and services provided by the mobile-government application. Almaiah [12] revealed that information quality has positive effect on impact on adoption of mobile information system in Jordan. Based on the current discussion, this research proposes:

H6: Perceived information quality will have a significant effect on mobile-government adoption

Availability of Resources (AVR): Availability of resources is defined as the availability and freedom of using mobile devices, mobile applications and internet with competitive features such as speed, access and cost. Shareef et al. [42] indicated that the availability of resources required for the use of mobile-government system has technological, behavioral, social, cultural and economic aspects. In general, where mobile devices, modern ICT and wireless internet are not available, the citizens are economically poor, less educated, unaware of modern technology, socially and culturally unfamiliar with modern technology, and lack the necessary skills to use technology. As a result, they also do not believe that they will receive benefits by using an mobile-government application. According Shareef et al. [42], there is strong relation between availability of resources and the adoption of e-government services. Availability of resources will increase the citizen's beliefs to adopt and use such mobile-government applications operated through mobile devices and wireless networks, which, in turn, encourages them to use mobile-government services. Thus:

H7: Availability of resources will have a significant effect on mobile-government adoption

Perceived Awareness (PA): Several researchers [14]; [50] have confirmed that perceived awareness is key element that motivates the citizens to use the e-government services. They indicated also the implementation of e-government systems can't be carried out smoothly without having regular awareness sessions in order to let people feel confident and motivated in using the e-government services [14];[50]. In a study conducted by Shareef et al. [42] revealed that perceived awareness has a significant relation with citizens' adoption of e-government services in Canada. Thus:

H8: perceived awareness will have a significant effect on mobile-government adoption 
Perceived Security (PSE): According to Safa [52], security is still considered to be one of the problems and obstructions for the continued use of IS, such as e-government and other online systems. Therefore, organizations need to ensure an efficient level of data privacy and data integrity, along with user authorization, to ensure security for all electronic transactions and online identity authentication [52]. This factor is considered a very important element in the implementation of e-government services to attain citizen's trust [42]. To this end, this research used perceived security factor as a construct in order to investigate how citizens respond to the government's efforts with regard to e-government services to be trustworthy. Perceived security is crucial to citizens' confidence regarding the safety of a mobile-government application. Based on previous research on security in mobile banking [53] and e-government [42] the security factor is the key contributors in improving trust among citizens as the authentication of egovernment financial transaction and protection of information in mobile banking application. Thus, this study propose that perceived security has a strong effect on perceived trust. Thus, this study proposes:

H9: Perceived security will have a significant effect on trust mobile-government services

H10: Perceived security will have a significant effect on mobile-government adoption

Performance Expectancy (PE): 'Performance Expectancy' is the "the extent to which a technology benefits the consumer when performing a particular activity" [30]. The construct of performance expectancy is commonly incorporated into the UTAUT to predict behavioural intention to use ICT systems [30]. For instance, Rodrigues, Gwendolyn, Sarabdeen, and Balasubramanian [54] used the UTAUT model to investigate usage in the United Arab Emirates (UAE). The results indicated that performance expectancy is linked to behavioural intention. Other researchers [17];[50] implemented the UTAUT model, and data supports the idea that performance expectancy and behavioural intention are connected. Therefore, it is proposed that:

H11: Performance expectancy will have a significant effect on mobile-government adoption.

Effort expectancy (EE): Effort expectancy is the "level of effort a consumer thinks a specific task will require" [30]. It is a vital construct of the UTAUT model and is used extensively to examine peoples' intentions related to new technology [30]. Muthu et al. [55] identified that in Malaysia effort expectancy was very influential in determining use of online services. Rodrigues et al. [54], also identified that effort expectancy is related to behavioural intention. Many similar studies apply the UTAUT, and there is evidence to support the idea that effort expectancy and behavioural intention are closely related. Therefore, the following hypotheses is proposed:

H12: Effort expectancy will have a significant effect on mobile-government adoption

Social Influence(SI): Social influence is the "extent that consumers feel other people think they ought to be using a specific technology" [30]. It is the third construct included in the UTAUT model, and other studies show that it can be quite influential in promoting use. Whereas in others, the results suggest that there is no significant relationship. Alshehri et al. [56] found no strong evidence of social influence in users in 
Saudi Arabia. It is possible that the influence varies from country to country and is dependent on culture. However, Muthu et al. [55], identified that it can be influential. Therefore, it is proposed that:

H13: Social influence will have a significant effect on mobile-government adoption

Facilitating Conditions (FC): FC is "a consumer's perception of the disposable resources and support when performing a task" [30]. In the model of UTAUT the impact of facilitating conditions was insignificant [30]. Several studies analyse the relationship between facilitating conditions and adoption of online government services. For example, Kurfalı et al. [24] applied the UTAUT model to investigate usage rates of services in Turkey. They revealed that facilitating conditions were beneficial to behavioural intention to adopt e-government services. Thus, it is proposed that:

H14: Facilitating condition will have a significant effect on mobile-government adoption

GAM model

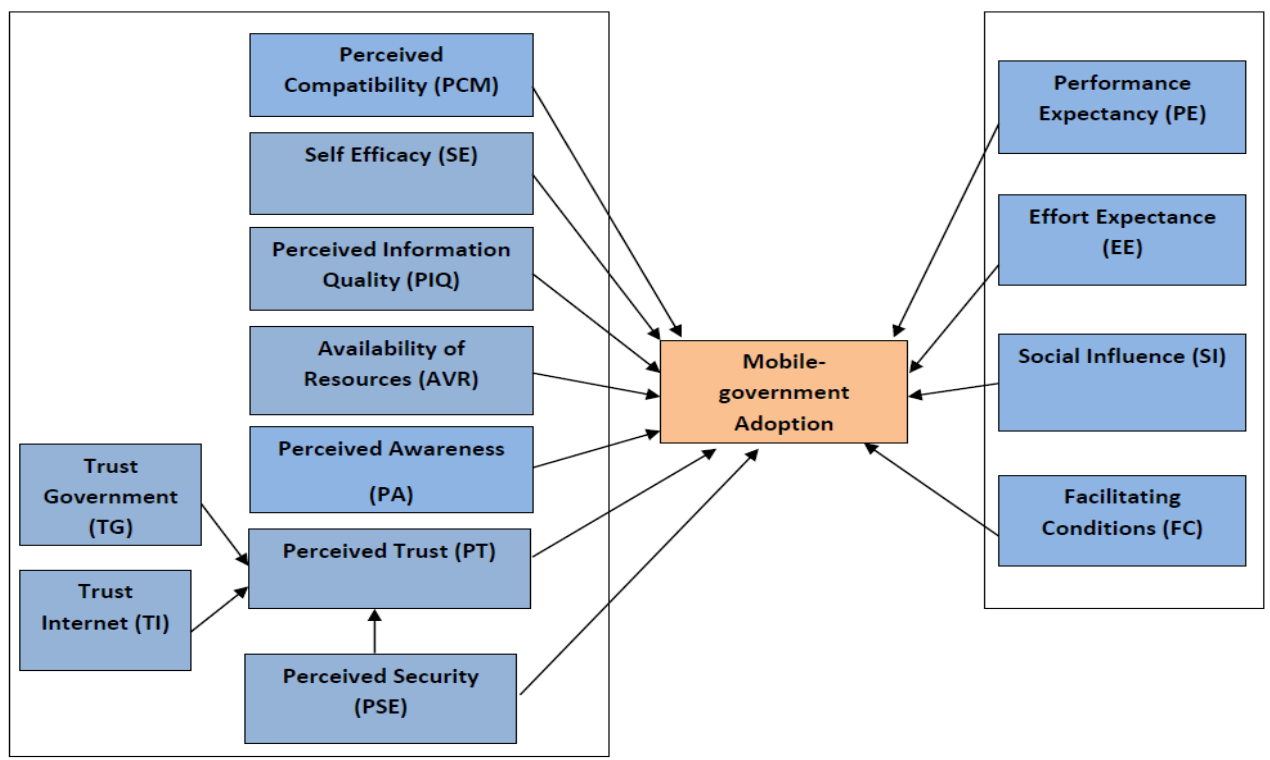

Fig. 1. The proposed research model

\section{$4 \quad$ Research Methodology}

\subsection{Sample}

As stated by Hair et al. [57], the sample should represent the population and must contain a sufficient number of respondents. When the number of participants is higher, it produces greater validity and more reliable results. According to Sekaran and Bougie 
[58], researchers can decide the size of the sample based on the population as shown in Table 2. In this paper, the researchers a large number of participants were contacted to obtain an optimal sample-size to make reliable estimates. According to the latest records published by the government of Jordan, the population in 2017 was 5,314,562. Therefore, choosing a sample of 807 respondents provides accurate answers, especially if the sample includes expert respondents [58]. Furthermore, using 807 respondents accurately reflects the population of Jordan, and is allows for a wide view of Jordanians ` opinions, expectations, satisfaction and adoption of online services [57].

Table 2. Determined sample size based on population size based on Sekaran and Bougie [57].

\begin{tabular}{|c|c|}
\hline Population & Sample size \\
\hline 10000 & 370 \\
\hline 15000 & 375 \\
\hline 20000 & 377 \\
\hline 30000 & 379 \\
\hline 40000 & 380 \\
\hline 50000 & 381 \\
\hline 100000 & 383 \\
\hline$>100000$ & $\mathbf{3 8 4}$ \\
\hline
\end{tabular}

807 questionnaires were sent to people in the public and private sector by email. The email addresses were provided by the Jordanian Chamber of Commerce and Industry. They were also sent to members of the Royal Scientific Society of Jordan, employees at the Ministry of Information, and Communications Technology of Jordan. The respondents were selected due to their experience in the technology industry. Participants were sent an email with a link to the questionnaire. 807 questionnaires were sent, and 320 completed questionnaires were received, showing a response rate of $40 \%$.

\subsection{Research instrument development}

A survey questionnaire was designed to identify what determines peoples` usage of online services in Jordan. The questionnaire contains 30 questions and fourteen variables. The questions were adapted from previous studies to ensure content validity. For example, Perceived Trust, Perceived Information Quality, Perceived Awareness, , Availability of Resources, Perceived Ability to Use, Perceived Compatibility, Self-Efficacy and Perceived Security were adapted from [10];[11];[3]. Facilitation conditions, performance expectancy, social influence and effort expectancy were taken from [30]. Trust of the Internet and trust of the government were taken from Lallmahomed et al. [25] (Please see Appendix A). The questionnaire includes five questions that identify the demographics of participants. The questionnaire uses a five-point Likert scale ranging from 'Strongly Disagree' to 'Strongly Agree'. The five-point Likert scale is believed to be more accurate than the three-point scale [59]. 


\subsection{Pilot test}

A pilot test was carried out on 35 respondents to determine how reliable the questionnaire was. Cronbach Alpha analysis was performed to examine the consistency of data. Table 4 indicates a reliable Cronbach Alpha value of $>0.7$.

\subsection{Data analysis}

The final stage involved examining the demographic data and conducting a reliability analysis to identify the consistency of the measurements. Two construct validity methods were used, they were convergent validity and discriminant validity. Finally, Structural Equation Modeling (SEM) analysis was done with SmartPLS version 3.0.

\section{$5 \quad$ Results}

\subsection{Respondents' demographic profile}

The profile background for the respondents is formed based on gender, age, level of study, sector and internet use. The profile background is summarized in Table 3. Based on the response of the respondents, among the respondents, $56.8 \%$ were males, and $43.2 \%$ were females. The age distribution was $34.3 \%$ for $22-32$ years old, $41.2 \%$ for $32-42$ years old, and $24.4 \%$ for those over 42 years of age. In addition, the majority of respondents were $70.3 \%$ for undergraduate level and the majority of them working in the public sector with $65.6 \%$. Also, $99.6 \%$ of our respondents use the Internet several times every day.

Table 3. Respondents' demographic profile

\begin{tabular}{|l|c|c|c|}
\hline \multirow{4}{*}{ Gender } & Classification & Frequency & Percent \\
& Male & 182 & 56.8 \\
& Female & 138 & 43.2 \\
\hline Age & $22-32$ & 110 & 34.3 \\
& $32-42$ & 132 & 41.2 \\
& & & 24.4 \\
\hline \multirow{3}{*}{ Level of study } & Over 42 & 78 & 70.3 \\
& Undergraduate & 225 & 29.7 \\
\hline \multirow{2}{*}{ Sector } & Postgraduate & 95 & 65.6 \\
\hline Mobile devices use & Public & 210 & 34.4 \\
\cline { 2 - 4 } & Private & 110 & 0.0 \\
\cline { 2 - 4 } & Several times weekly & 0 & 0.06 \\
\cline { 2 - 4 } & Several times every day & 318 & 99.3 \\
\hline
\end{tabular}




\subsection{Reliability analysis}

Before conducting the primary analysis, the research instrument must be verified. A reliability analysis measures the consistency between items in the same construct using Cronbach's Alpha. Hair et al. [57], states that ideally a value of above 0.7 is required to be classed as highly reliable, and values between 0.6 and 0.7 are deemed to be acceptable. Table 4 shows the reliability values for all constructs was greater than 0.7 , and that questionnaire is considered reliable.

Table 4. Results of reliability and convergent validity analysis

\begin{tabular}{|l|c|c|}
\hline \multicolumn{1}{|c|}{ Variables } & Cronbach's Alpha (a>0.7) & $\begin{array}{c}\text { Average Variance Extracted } \\
(\mathbf{A V E}>\mathbf{0 . 5})\end{array}$ \\
\hline Perceived Compatibility (PCM) & 0.91 & 0.74 \\
\hline Perceived Trust (PT) & 0.92 & 0.76 \\
\hline Trust of Internet (TI) & 0.90 & 0.72 \\
\hline Trust of Government (TG) & 0.89 & 0.73 \\
\hline Self-Efficacy (SE) & 0.86 & 0.70 \\
\hline $\begin{array}{l}\text { Perceived Information Quality } \\
\text { (PIQ) }\end{array}$ & 0.92 & 0.75 \\
\hline $\begin{array}{l}\text { Availability of Resources } \\
\text { (AVR) }\end{array}$ & 0.89 & 0.72 \\
\hline Perceived Awareness (PA) & 0.83 & 0.65 \\
\hline Perceived Security (PSE) & 0.86 & 0.71 \\
\hline Performance Expectancy (PE) & 0.88 & 0.73 \\
\hline Effort Expectancy (EE) & 0.90 & 0.72 \\
\hline Social Influence (SI) & 0.77 & 0.60 \\
\hline Facilitating Conditions (FC) & 0.85 & 0.70 \\
\hline
\end{tabular}

\subsection{Convergent validity and Discriminant validity analysis}

For the discriminant validity analysis, the square root of AVE was taken to correlate the latent constructs. Table 5 shows that the square root of the AVE for all constructs is higher than the pairwise correlations. Therefore, the psychometric characteristics of the instrument are acceptable in terms of discriminant validity [60].

In this study, the validity of constructs was assessed for convergent validity and discriminant validity. For the convergent validity, the results in Table 4 show that the average variance extracted (AVE) was above 0.5. Hair et al. [57], state that an acceptable level of variance is higher than 0.5 .

\subsection{Model-fit indices assessment}

The model testing involves assessing how well suited the research instrument is in relation to the study data. For this study, the Goodness of Fit (GoF) method was used. Tabachnick and Fidell [61] believe that the Goodness of Fit (GoF) is an important stage of testing. In this study, a confirmatory factor analysis (CFA) was used to identify the model-fit indices of the research model. Table 6 illustrates that overall fit of the revised structural model indicated that the hypothesised structural model provided a good fit to the data. 
Table 5. Analysis of Discriminant validity matrix

\begin{tabular}{|l|c|c|c|c|c|c|c|c|c|c|c|c|c|}
\hline \multicolumn{1}{|c|}{ Variables } & PCM & PT & TI & TG & SE & PIQ & AVR & PA & PSE & PE & EE & SI & FC \\
\hline $\begin{array}{l}\text { Perceived Com- } \\
\text { patibility (PCM) }\end{array}$ & $\mathbf{0 . 8 9}$ & & & & & & & & & & & & \\
\hline $\begin{array}{l}\text { Perceived Trust } \\
\text { (PT) }\end{array}$ & .445 & $\mathbf{0 . 9 1}$ & & & & & & & & & & & \\
\hline $\begin{array}{l}\text { Trust of Internet } \\
\text { (TI) }\end{array}$ & .482 & .377 & $\mathbf{0 . 8 7}$ & & & & & & & & & & \\
\hline $\begin{array}{l}\text { Trust of Gov- } \\
\text { ernment (TG) }\end{array}$ & .473 & .560 & .439 & $\mathbf{0 . 8 2}$ & & & & & & & & & \\
\hline $\begin{array}{l}\text { Self-Efficacy } \\
\text { (SE) }\end{array}$ & .384 & .445 & .445 & .473 & $\mathbf{0 . 8 0}$ & & & & & & & & \\
\hline $\begin{array}{l}\text { Perceived Infor- } \\
\text { mation Quality } \\
\text { (PIQ) }\end{array}$ & .566 & .408 & .482 & .408 & .377 & $\mathbf{0 . 9 0}$ & & & & & & & \\
\hline $\begin{array}{l}\text { Availability of } \\
\text { Resources } \\
\text { (AVR) }\end{array}$ & .338 & .502 & .473 & .445 & .560 & .377 & $\mathbf{0 . 8 6}$ & & & & & & \\
\hline $\begin{array}{l}\text { Perceived } \\
\text { Awareness (PA) }\end{array}$ & .408 & .384 & .408 & .408 & .445 & .560 & .482 & $\mathbf{0 . 8 1}$ & & & & & \\
\hline $\begin{array}{l}\text { Perceived Secu- } \\
\text { rity (PSE) }\end{array}$ & .502 & .566 & .502 & .502 & .482 & .473 & .473 & .502 & $\mathbf{0 . 8 8}$ & & & & \\
\hline $\begin{array}{l}\text { Performance } \\
\text { Expectancy } \\
\text { (PE) }\end{array}$ & .463 & .338 & .533 & .445 & .473 & .377 & .772 & .384 & .502 & $\mathbf{0 . 8 5}$ & & & \\
\hline $\begin{array}{l}\text { Effort Expec- } \\
\text { tancy (EE) }\end{array}$ & .377 & .445 & .515 & .408 & .445 & .560 & .384 & 4.83 & .291 & .445 & $\mathbf{0 . 8 7}$ & & \\
\hline $\begin{array}{l}\text { Social Influence } \\
\text { (SI) }\end{array}$ & .560 & .482 & .455 & .502 & .408 & .445 & .566 & .301 & 4.75 & .408 & .377 & $\mathbf{0 . 7 4}$ & \\
\hline $\begin{array}{l}\text { Facilitating } \\
\text { Conditions (FC) }\end{array}$ & .473 & .473 & .459 & .291 & .502 & .408 & .338 & .345 & .421 & .502 & .560 & .445 & $\mathbf{0 . 8 7}$ \\
\hline
\end{tabular}

Table 6. Model fit indices analysis

\begin{tabular}{|l|c|c|}
\hline \multicolumn{1}{|c|}{ Fit index } & Research model & Recommended values \\
\hline $\mathrm{x}^{2} /$ d.f. & 4.01 & $<5.00$ \\
\hline GFI & 0.921 & $>0.90$ \\
\hline AGFI & 0.876 & $>0.80$ \\
\hline RMSEA & 0.033 & $<0.06$ \\
\hline SRMR & 0.072 & $<0.08$ \\
\hline NFI & 0.932 & $>0.90$ \\
\hline NNFI & 0.941 & $>0.90$ \\
\hline CFI & 0.923 & $>0.90$ \\
\hline IFI & 0.911 & $>0.90$ \\
\hline
\end{tabular}

\subsection{Path analysis of Causal relationships}

Following confirmation that the model was suitable for the data, the SEM analysis was carried out with SmartPLS version 3.0. For analysing the collected data, path analysis of structural equation modeling (SEM) was used. This kind of analysis method has 
been used in many previous research such mobile banking adoption [53] and e-government adoption [42]. Therefore, this type of analysis method is suitable for this study.

Table 7 contains data obtained from the hypotheses testing. In total 14 hypotheses were proposed, to test the effects of perceived trust, perceived information quality, perceived awareness, , availability of resources, perceived ability to use, perceived compatibility, self efficacy, perceived security, performance expectancy, effort expectancy, social influence and facilitating conditions on the adoption of e-government services.

All hypotheses except for H13 were supported, meaning that 13 out of 14 factors were shown to be relevant in explaining the adoption of mobile-government services as shown in Figure 2. Perceived Information Quality (PIQ) and Perceived Security (PSE) proved to be the most important factors in determining the adoption of mobile-government services with a results of $(\mathrm{H} 6, \beta=0.502)$ and $(\mathrm{H} 10, \beta=0.527)$. In addition, this research explains the relationship between trust of internet, trust of government and perceived security with perceived trust which is something that has not been tested in mobile-government adoption context. The results indicate that trust of internet, trust of government and perceived security have significant effect on increasing the perceived trust among users.

\section{Discussions}

Few efforts have actually been done in studying the adoption and acceptance of new mobile technologies and applications for governments, banking and others e.g., [6];[54]. Also, it has been frequently recommended for more extensions of some models and theories, and advised to apply or use such models and theories to the new areas of ICT technologies and other evolving domains such as smart government or mobilegovernment e.g., [42]. Therefore, this study attempts to fill the existing gap in the literature through combining The UTAUT model and GAM model with adding new constructs like trust of internet, trust of government and perceived security to investigate the main antecedents of mobile-government services adoption. In the following sections, the discussion of the results are presented in details.

\subsection{Explaining the effect of GAM and UTAUT factors on adoption of mobile- government services}

The relationship between Perceived Compatibility (PCM) factor and adoption of Mobile-government services: When the mobile government services are perceived to be compatible with the needs and perceptions of potential users, it is more likely to be accepted by the users and thus, the adoption process of mobile government services will be succeed. From another viewpoint, many researchers e.g., [42] stated that if the system services and characteristics reflect the user's needs and perceptions, this will create high compatibility among citizens to adopt mobile-government applications.

The results indicate that there is a significant relationship between the perceived compatibility and mobile-government adoption among citizens $(\mathbf{H 1}, \boldsymbol{\beta}=0.455, \mathbf{P}=$ 
001). Based on that, it can be inferred that users relate this perceived compatibility factor with the adoption of mobile-government services. This result is consistent with a previous study conducted for studying the adoption of e-government services [42].

\begin{tabular}{|l|c|c|c|}
\hline Hypothesised Path & $\boldsymbol{\beta}$ & P & Supported \\
\hline $\begin{array}{l}\text { H1: PCM } \\
\text { tion of Mobile-govern- } \\
\text { ment services }\end{array}$ & 0.455 & 001 & Yes \\
\hline
\end{tabular}

The relationship between Perceived Trust (PT) factor and adoption of Mobilegovernment services: The results of this study reveal that both factors of perceived trust of the Internet and perceived trust of the governments were an important antecedents of perceived trust $(\mathbf{H 2}, \boldsymbol{\beta}=0.497, \mathbf{P}=001)$ and $(\mathbf{H 3}, \boldsymbol{\beta}=0.434, \mathbf{P}=001)$. This means that are both significant in promoting citizens' trust to adopt and use mobilegovernment services. One potential cause of the disparity between number of services and number of users of mobile-government services is the trust or lack of trust that people hold towards the Internet. Therefore, if the level of trust can be increased, it may lead to less reluctance to use internet services and increased user numbers.

\begin{tabular}{|c|c|c|c|}
\hline Hypothesised Path & $\boldsymbol{\beta}$ & P & Supported \\
\hline $\mathrm{H} 2 \mathrm{TI} \longrightarrow$ Trust of Mobile-government services & 0.497 & 001 & Yes \\
\hline $\mathrm{H} 3: \mathrm{TG} \longrightarrow$ Trust of Mobile-government services & 0.434 & 001 & Yes \\
\hline
\end{tabular}

The results also show that the standardised regression weight for the perceived trust factor to adopt mobile-government services was $(\boldsymbol{\beta}=0.485)$. This suggested that this path was statistically significant at $\mathbf{P}=0.001$ level; hence, it showed strong support for the adoption of hypothesis H4. These results indicate that trust has a strong significant effect on the adoption of mobile-government services. This implies that increase in the trust would positively influence a user's intention towards adoption of the system.

\begin{tabular}{|c|c|c|c|}
\hline Hypothesised Path & $\boldsymbol{\beta}$ & P & Supported \\
\hline H4: PT $\longrightarrow$ Adoption of Mobile-government services & 0.485 & 001 & Yes \\
\hline
\end{tabular}

The relationship between Self-Efficacy (SE) factor and adoption of Mobile-government services: This hypothesis tested the effect of technological self-efficacy on adoption of mobile-government services. The results show that technological self-efficacy strongly influences adoption of mobile-government services. The standardised regression $(\beta)$ for the self-efficacy factor to the adoption of mobile-government services was $((\boldsymbol{\beta}=0.477)$, and significant at the $(\mathbf{p}=0.001)$. These results demonstrate strong support for the H5. This implies that high technological self-efficacy will lead to positively influence the user's intention towards adopting the mobile-government applications. Interestingly, this result is unlike previous study conducted by Shareef et al. [42], 
who found that self-efficacy is not an important factor to adopt e-government services. In summary, the result suggests that technological self-efficacy is a major determinant of mobile-government adoption.

\begin{tabular}{|c|c|c|c|}
\hline Hypothesised Path & 及 & P & Supported \\
\hline H5: SE $\longrightarrow$ Adoption of Mobile-government services & 0.477 & 0.001 & Yes \\
\hline
\end{tabular}

The relationship between Perceived Information Quality (PIQ) factor and adoption of Mobile-government services: This research examined the effect of perceived information quality factor on adoption of mobile-government services. Perceived information quality in this study was measured based on five quality dimensions, like accuracy, completeness, timeliness, relevance, and efficiency of information. The results indicate that information quality is one of the most influential factors on the adoption of mobile-government services $(\mathbf{H 6}, \boldsymbol{\beta}=0.502, \mathbf{P}<0.001)$. This means that when information quality of mobile-government applications is user-friendly, richness of government information and services, accurate, designed with a correct design principle and provides up-to-date information, the adoption rates of mobile-government services will increase. This is consistent with work done by [54].

\begin{tabular}{|c|c|c|c|}
\hline Hypothesised Path & B & P & Supported \\
\hline H6: PIQ $\longrightarrow$ Adoption of Mobile-government services & 0.502 & 0.001 & Yes \\
\hline
\end{tabular}

The relationship between Availability of Resources (AVR) factor and adoption of Mobile-government services: The results show that the standardised regression weight for the availability of resources factor to adopt mobile-government services was $(\boldsymbol{\beta}=0.443)$. This suggested that this path was statistically significant at $\mathbf{P}=0.001$ level; hence, it showed strong support for the adoption of hypothesis $\mathbf{H 7}$. These results indicate that availability of resources has a strong significant effect on the adoption of mobile-government services. This implies that when mobile devices, mobile applications, modern ICT and wireless internet are available, the citizens are familiar with modern technology, aware of modern mobile technologies and have the necessary skills to use technology. As a result, they will believe that they will receive benefits by using an mobile-government application, which, in turn, encourages them to use mobile-government services.

\begin{tabular}{|c|c|c|c|}
\hline Hypothesised Path & $\boldsymbol{\beta}$ & $\mathbf{P}$ & Supported \\
\hline H7: AVR $\longrightarrow$ Adoption of Mobile-government services & 0.443 & 0.001 & Yes \\
\hline
\end{tabular}

The relationship between Perceived Awareness (PA) factor and adoption of Mobile-government services: The results indicate that there is a significant relationship between the perceived awareness and adoption of mobile-government among citizens (H8, $\boldsymbol{\beta}=0.421, \mathbf{P}=001)$. Based on that, it can be inferred that perceived awareness 
factor is key element that motivates the citizens to adopt mobile-government services. This result is consistent with a previous study conducted for studying the adoption of e-government services [42]. When governments pay attention to awareness sessions as a means to motivate citizens to use mobile-government applications, and use the social media applications to promote the importance of mobile-government applications that offer them several benefits, they will believe that they will receive benefits by using an mobile-government application, which, in turn, motivates them to adopt mobile-government services.

\begin{tabular}{|c|c|c|c|}
\hline Hypothesised Path & $\boldsymbol{\beta}$ & P & Supported \\
\hline H8: PA $\longrightarrow$ Adoption of Mobile-government services & 0.421 & 0.001 & Yes \\
\hline
\end{tabular}

The relationship between Perceived Security (PSE) factor and adoption of Mobile-government services: The hypotheses tested the effect of perceived security on perceived trust and adoption of mobile-government services. The results show that perceived security factor is the key contributor in improving trust among citizens (H9, $\boldsymbol{\beta}=0.501, \mathbf{P}<0.001)$. This is consistent with work done by [54].

\begin{tabular}{|c|c|c|l|}
\hline Hypothesised Path & $\boldsymbol{\beta}$ & P & Supported \\
\hline H9: PSE $\longrightarrow$ Trust of Mobile-government services & 0.501 & 0.001 & Yes \\
\hline
\end{tabular}

In addition, the results indicate that perceived security is one of the most critical factors that influence on the adoption of mobile-government services $(\mathbf{H 1 0}, \boldsymbol{\beta}=0.527$, $\mathbf{P}<0.001$ ). This means When citizens have high confidence regarding the safety of financial transactions that are performed through a mobile-government application, and ensure that their information is well protected, this will contribute in improving citizens' trust, and thus, the adoption rates of mobile-government services will increase. Therefore, this study suggest that governments need to ensure an efficient level of data privacy and data integrity, along with user authorization, to ensure security for all electronic transactions and online identity authentication.

\begin{tabular}{|c|c|c|c|}
\hline Hypothesised Path & $\boldsymbol{\beta}$ & P & Supported \\
\hline H10: PSE $\longrightarrow$ Adoption of Mobile-government services & 0.527 & 0.001 & Yes \\
\hline
\end{tabular}

The relationship between Performance Expectancy (PE) factor and adoption of Mobile-government services: This research examined the effect of performance expectancy factor on adoption of mobile-government services. The results reinforce the idea that performance expectancy factor has a significant effect on adoption of mobilegovernment services. The results support the hypothesis H11, and the result of $(\boldsymbol{\beta}=0.484, \mathbf{P}<0.05)$ shows that people feel using a mobile-government services could be beneficial to their interactions with government. Some of the specific benefits are time 
and cost reductions, and improvements in the quality of government services. This result is similar to that of previous research [6].

\begin{tabular}{|l|c|c|c|}
\hline \multicolumn{1}{|c|}{ Hypothesised Path } & $\boldsymbol{\beta}$ & P & Supported \\
\hline $\begin{array}{l}\text { H11: PE } \\
\text { vices }\end{array}$ Adoption of Mobile-government ser- & 0.484 & 0.001 & Yes \\
\hline
\end{tabular}

The relationship between Effort Expectancy (EE) factor and adoption of Mobile-government services: The results show that effort expectancy $(\boldsymbol{\beta}=0.469, \mathbf{P}<0.05)$ is also influential in determining adoption of mobile-government services. This supports (H12), which states that effort expectancy has a significant effect on adoption of mobile-government services. In this research, effort expectancy factor is measured through the perception of ease, which is related to how easy people find mobile-government applications to use or become proficient in.

\begin{tabular}{|c|c|c|c|}
\hline Hypothesised Path & $\boldsymbol{\beta}$ & P & Supported \\
\hline H12: EE $\longrightarrow$ Adoption of Mobile-government services & 0.469 & 0.001 & Yes \\
\hline
\end{tabular}

The relationship between Social influence (SI) factor and adoption of Mobilegovernment services: Unlike previous studies, this research indicates that social influence factor is not significantly linked to adopt online government systems like mobilegovernment applications in Jordan. One advantage of social influence that Jordan is perhaps missing out on, is that as more people use a service, and word spreads, the value of the service usually increases [17]. Because use of online services is relatively low in Jordan, and because of the absence of high user numbers, social influence is not considered significant because there simply are not enough users for it to have a significant impact $(\boldsymbol{\beta}=0.021, \mathbf{P}>0.05)$.

\begin{tabular}{|c|c|c|c|}
\hline Hypothesised Path & $\boldsymbol{\beta}$ & $\mathbf{P}$ & Supported \\
\hline H13: SI $\longrightarrow$ Adoption of Mobile-government services & 0.021 & 0.05 & No \\
\hline
\end{tabular}

The relationship between Facilitating conditions (FC) factor and adoption of Mobile-government services: Finally, this research tested the effect of facilitating conditions factor on adoption of mobile-government services. The results show that facilitating conditions factor and adoption of mobile-government services are closely related $(\boldsymbol{\beta}=0.481, \mathbf{P}<0.001)$. This factor was assessed by examining the available technical resources and support required to use mobile-government services. It appears the Jordanian government have the right idea and are currently investing large sums of money to improve ICT infrastructure. This could also be further improved by increasing access to the Internet, especially in public places. The data support the hypothesis (H14), and the result is consistent with previous work by [24] carried out in Turkey. 


\begin{tabular}{|c|c|c|c|}
\hline Hypothesised Path & $\boldsymbol{\beta}$ & P & Supported \\
\hline H14: FC $\longrightarrow$ Adoption of Mobile-government services & 0.481 & 0.001 & No \\
\hline
\end{tabular}

\section{$7 \quad$ Theoretical and Practical Implications}

This study is among the first on mobile-government adoption that provides useful guidance for both researchers and practitioners to explain which critical factors should be considered for mobile-government services adoption. For theoretical and practical implications, this study focuses on factors that cover several aspects like technological, social, trust, individual and information quality characteristics affecting users' adoption of mobile-government services. Therefore, the finding of this research will serve as an important reference for policy makers, for the purpose of the strategic vision.

This research made a significant contribution, through proposing an integrated model that combine two important models, namely, UTAUT model and GAM model, which in turn, allow researchers to test new factors contributing the success of mobilegovernment services adoption. According to previous literature, most researchers studied mobile-government adoption from other models such as TAM, TAM2, UTAUT and etc, while less attention was accorded to the GAM model in the mobile-government context. Therefore, the researcher employed both UTAUT and GAM models to the research, in order to cover all aspects of mobile-government services adoption. In addition, this study add new contribution, through adding new factors affecting mobilegovernment adoption like (trust of internet, trust of government and perceived security). Based on previous literature, most researchers investigated mobile-government adoption from some factors such as organizational, cultural and etc, and less effort was conducted to study the effect of trust of internet, trust of government and perceived security factors on mobile-government adoption. Thus, the present study shed light on the most important factors reflecting mobile-government adoption.

Moreover, this study can be a great reference for researchers, which will enable them to get better acquainted with the key aspects of the mobile-government services adoption in Jordan, through the findings of this study. Therefore, all solutions and technical issues with regards to the implementation of mobile-government services are easily understandable, making them useful, more effective, and reliable. The findings indicated how the users trust the mobile-government system based on a significant correlation between the trust of internet, trust of government, perceived security and perceived trust factors and adoption of mobile-government, and hence the government should exploit this advantage by providing accurate, clear, complete and current information, and to open online communication $24 / 7$ with users, to answer all their inquiries regarding any government services via mobile-government application. Such a policy will enhance user satisfaction and increase confidence in the service provider. Furthermore, the quality of information, compatibility, availability of resources and perceived security factors will provide greater reliability in order to perform online transactions through the 
mobile application. Although there is no issue with regard to the system security, according to the case study, the government should ensure more advanced security standards through laws and legislations, to maintain a positive relationship with users.

Furthermore, important factor was discovered through the proposed model for mobile-government adoption, which related to training and awareness sessions. The findings suggest that the governments need to pay attention to awareness sessions as a means to motivate citizens to use mobile-government application, and to use the mobile social media applications to promote the importance of mobile-government in future strategic vision for all countries. Finally, the findings also suggest that technological self-efficacy is found to be a significant predictor of mobile-government adoption. Accordingly, this study confirms the findings of the previous research on the importance of IT skills among users and government employees, and those who suffer from such skills should be paid attention to remove any barriers that prevent the successful adoption of mobile-government and e-government services.

\section{Conclusions and Future Research}

This research examined the mobile-government services adoption, using both UTAUT and GAM models for explaining the key factors that affect on adoption of mobile-government services. As a result, the study identified the critical factors that influence users' to adopt the system, and developed a model as a powerful tool that assists in the adoption process of mobile-government applications. The novelty of this research will be an added value to the body of knowledge and its implications will be vital for researchers and decision/policy makers who are willing to make a change.

This research adds important contributions to existing research into mobile-government services adoption through the following results. First, the results show that GAM model factors like information quality, trust and technological self-efficacy were the most significant determiners of mobile-government adoption. Second, this research confirms that awareness, availability of resources and system compatibility are influential factors in the adoption of mobile-government services. Third, in reference to the UTAUT model constructs, the results indicate that performance expectancy, effort expectancy and facilitating conditions all contribute to the adoption of mobile-government application. While, social influence is not shown to be significantly important. Fourth, the effect of the trust of internet, trust of government and perceived security on the adoption of mobile-government was significant for users. This indicates that as trust increases, users are more willing to adopt and use mobile-government services.

The unique element of this research is the integration of new constructs from GAM model like information quality, compatibility, awareness, technological self-efficacy, trust of internet and trust of government to UTAUT model. Therefore, it is believed that this research can serve as a foundation for future research on citizens' adoption of mobile-government services, and hence, governments will have the facts related to factors affecting users' adoption of mobile-government services. Therefore, the governments will be able to focus on each factor and make improvements. Finally, the main role of this research also was to find out the major points that will be helpful for the policy 
makers in the governments, and to be considered as useful guidance for them in improving the adoption of mobile-government services.

\section{$9 \quad$ References}

[1] Al-Khamayseh, S. A. T. (2009). Successful transition to mobile government (m-government): an adaptive framework (Doctoral dissertation).

[2] Abdelghaffar, H., \& Magdy, Y. (2012). The adoption of mobile government services in developing countries: The case of Egypt. International Journal of Information and Communication Technology Research, 2(4).

[3] Al-Khamayseh, S. A. T. (2009). Successful transition to mobile government (m-government): an adaptive framework (Doctoral dissertation).

[4] Sharma, S. K., Al-Badi, A., Rana, N. P., \& Al-Azizi, L. (2018). Mobile applications in government services (mG-App) from user's perspectives: A predictive modelling approach. Government Information Quarterly, 35(4), 557-568. https://doi.org/10.1016/j.giq.2018.07. $\underline{002}$

[5] Tavakoli, F., Ghasemi, M., \& Yaghoubi, Y. (2016). A Survey of Technical Factors Affecting Mobile Government Implementation in the Public Service of Fars Province. Journal of productivity and development, 2(4), 76-85.

[6] Rana, N., Janssen, M., Sahu, G. P., Baabdullah, A., \& Dwivedi, Y. (2019, January). Citizens' Perception About M-Government Services: Results from an Exploratory Survey. In Proceedings of the 52nd Hawaii International Conference on System Sciences. https://doi. org/10.24251/hicss.2019.405

[7] Almaiah, M. A., Alamri, M. M., \& Al-Rahmi, W. (2019). Applying the UTAUT Model to Explain the Students' Acceptance of Mobile Learning System in Higher Education. IEEE Access, 7, 174673-174686. https://doi.org/10.1109/access.2019.2957206

[8] Almaiah, M. A., \& Alyoussef, I. Y. (2019). Analysis of the Effect of Course Design, Course Content Support, Course Assessment and Instructor Characteristics on the Actual Use of ELearning System. IEEE Access, 7, 171907-171922. https://doi.org/10.1109/ access.2019.2956349

[9] Almaiah, M. A., Alamri, M. M., \& Al-Rahmi, W. M. (2019). Analysis the Effect of Different Factors on the Development of Mobile Learning Applications at different stages of usage. IEEE Access. https://doi.org/10.1109/access.2019.2963333

[10] Shareef, M. A., Archer, N., \& Dwivedi, Y. K. (2012). Examining adoption behavior of mobile government. Journal of Computer Information Systems, 53(2), 39-49.

[11] Almaiah, M. A., Jalil, M. A., \& Man, M. (2016). Extending the TAM to examine the effects of quality features on mobile learning acceptance. Journal of Computers in Education, 3(4), 453-485. https://doi.org/10.1007/s40692-016-0074-1

[12] Almaiah, M. A. (2018). Acceptance and usage of a mobile information system services in University of Jordan. Education and Information Technologies, 23(5), 1873-1895. https:// doi.org/10.1007/s10639-018-9694-6

[13] Borucki, C., Arat, S., \& Kushchu, I. (2005, July). Mobile government and organizational effectiveness. In Proceedings of the First European Conference on Mobile Government, Brighton, UK: Mobile Government Consortium International (pp. 56-66). https://doi.org/ 10.4018/978-1-59140-884-0.ch007

[14] Almarashdeh, I., \& Alsmadi, M. K. (2017). How to make them use it? Citizens acceptance of M-government. Applied Computing and Informatics, 13(2), 194-199. https://doi.org/10. $\underline{\text { 1016/j.aci.2017.04.001 }}$ 
[15] El-Kiki, T., \& Lawrence, E. (2006, August). Mobile user satisfaction and usage analysis model of mgovernment services. In Proceedings of EURO mGOV (pp. 91-102).

[16] Sheng, H., \& Trimi, S. (2008). M-government: technologies, applications and challenges. Electronic Government, An International Journal, 5(1), 1-18.

[17] Abu-Shanab, E., \& Haider, S. (2015). Major factors influencing the adoption of m-government in Jordan. Electronic Government, an International Journal, 11(4), 223-240. https:// doi.org/10.1504/eg.2015.071394

[18] Alomari, M. (2018). Mobile Government Adoption: Citizen-Centric Approach.

[19] Almaiah, M. A., \& Alismaiel, O. A. (2019). Examination of factors influencing the use of mobile learning system: An empirical study. Education and Information Technologies, 24(1), 885-909. https://doi.org/10.1007/s10639-018-9810-7

[20] Almaiah, M. A., \& Al Mulhem, A. (2019). Analysis of the essential factors affecting of intention to use of mobile learning applications: A comparison between universities adopters and non-adopters. Education and Information Technologies, 24(2), 1433-1468. https://doi. org/10.1007/s10639-018-9840-1

[21] Alenezi, H., Tarhini, A., Masa'deh, R. E., Alalwan, A., \& Al-Qirim, N. (2017). Factors Affecting the Adoption of e-Government in Kuwait: A Qualitative Study. Electronic Journal of e-Government, 15(2).

[22] Alshehri, M., Drew, S., \& AlGhamdi, R. (2013). Analysis of citizens acceptance for e-government services: applying the UTAUT model. arXiv preprint arXiv:1304.3157.

[23] Lin, F., Fofanah, S. S., \& Liang, D. (2011). Assessing citizen adoption of e-Government initiatives in Gambia: A validation of the technology acceptance model in information systems success. Government Information Quarterly, 28(2), 271-279. https://doi.org/10.1016/ j.giq.2010.09.004

[24] Kurfalı, M., Arifoğlu, A., Tokdemir, G., \& Paçin, Y. (2017). Adoption of e-government services in Turkey. Computers in Human Behavior, 66, 168-178. https://doi.org/10.1016/ j.chb.2016.09.041

[25] Lallmahomed, M. Z., Lallmahomed, N., \& Lallmahomed, G. M. (2017). Factors influencing the adoption of e-Government services in Mauritius. Telematics and Informatics, 34(4), 5772. https://doi.org/10.1016/j.tele.2017.01.003

[26] Akhtar Shareef, M., Kumar, V., Kumar, U., \& Dwivedi, Y. (2014). Factors affecting citizen adoption of transactional electronic government. Journal of Enterprise Information Management, 27(4), 385-401. https://doi.org/10.1108/jeim-12-2012-0084

[27] Liu, Y., Li, H., Kostakos, V., Goncalves, J., Hosio, S., \& Hu, F. (2014). An empirical investigation of mobile government adoption in rural China: A case study in Zhejiang province. Government Information Quarterly, 31(3), 432-442. https://doi.org/10.1016/j.giq. 2014.02.008

[28] Wang, C. (2014). Antecedents and consequences of perceived value in Mobile Government continuance use: An empirical research in China. Computers in Human Behavior, 34, 140147. https://doi.org/10.1016/j.chb.2014.01.034

[29] Ahmad, S. Z., \& Khalid, K. (2017). The adoption of M-government services from the user's perspectives: Empirical evidence from the United Arab Emirates. International Journal of Information Management, 37(5), 367-379. https://doi.org/10.1016/j.ijinfmgt.2017. $\underline{03.008}$

[30] Venkatesh, V., Morris, M. G., Davis, G. B., \& Davis, F. D. (2003). User acceptance of information technology: Toward a unified view. MIS quarterly, 425-478. https://doi.org/10. 2307/30036540

[31] Davis, F. D. (1989). Perceived usefulness, perceived ease of use, and user acceptance of information technology. MIS quarterly, 319-340. https://doi.org/10.2307/249008 
[32] Fishbein, M., Jaccard, J., Davidson, A. R., Ajzen, I., \& Loken, B. (1980). Predicting and understanding family planning behaviors. In Understanding attitudes and predicting social behavior. Prentice Hall.

[33] Ajzen, I. (1991). The theory of planned behavior. Organizational behavior and human decision processes, 50(2), 179-211. https://doi.org/10.1016/0749-5978(91)90020-t

[34] Almaiah, M. A., \& Man, M. (2016). Empirical investigation to explore factors that achieve high quality of mobile learning system based on students' perspectives. Engineering science and technology, an international journal, 19(3), 1314-1320. https://doi.org/10.1016/ j.jestch.2016.03.004

[35] Almaiah, M. A., \& Jalil, M. A. (2014). Investigating Students' Perceptions on Mobile Learning Services. iJIM, 8(4), 31-36. https://doi.org/10.3991/ijim.v8i4.3965

[36] Almaiah, M. A., Jalil, M. A., \& Man, M. (2016). Preliminary study for exploring the major problems and activities of mobile learning system: A case study of Jordan.

[37] Al-Mamary, Y. H., Shamsuddin, A., \& Aziati, N. (2015). Investigating the key factors influencing on management information systems adoption among telecommunication companies in Yemen: the conceptual framework development. International Journal of Energy, Information and Communications, 6(1), 59-68. https://doi.org/10.14257/ijeic.2015.6.1.06

[38] Surendran, P. (2012). Technology acceptance model: A survey of literature. International Journal of Business and Social Research, 2(4), 175-178.

[39] Abdullah, F., \& Ward, R. (2016). Developing a General Extended Technology Acceptance Model for E-Learning (GETAMEL) by analysing commonly used external factors. Computers in Human Behavior, 56, 238-256. https://doi.org/10.1016/j.chb.2015.11.036

[40] Wu, M. Y., Chou, H. P., Weng, Y. C., \& Huang, Y. H. (2011). TAM-2 based study of website user behavior-using web 2.0 websites as an example. WSEAS Transactions on Business and Economics, 4(8), 133-51.

[41] Walldén, S., Mäkinen, E., \& Raisamo, R. (2016). A review on objective measurement of usage in technology acceptance studies. Universal Access in the Information Society, 15(4), 713-726. https://doi.org/10.1007/s10209-015-0443-y

[42] Shareef, M. A., Kumar, V., Kumar, U., \& Dwivedi, Y. K. (2011). e-Government Adoption Model (GAM): Differing service maturity levels. Government information quarterly, 28(1), 17-35. https://doi.org/10.1016/j.giq.2010.05.006

[43] Shareef, M. A., Kumar, V., Dwivedi, Y. K., \& Kumar, U. (2016). Service delivery through mobile-government (mGov): Driving factors and cultural impacts. Information Systems Frontiers, 18(2), 315-332. https://doi.org/10.1007/s10796-014-9533-2

[44] Almaiah, M. A., \& Almulhem, A. (2018). A conceptual framework for determining the success factors of e-learning system implementation using Delphi technique. Journal of Theoretical and Applied Information Technology, 96(17).

[45] Rogers, E. M. (1995). Diffusion of Innovations: modifications of a model for telecommunications. In Die diffusion von innovationen in der telekommunikation (pp. 25-38). Springer, Berlin, Heidelberg. https://doi.org/10.1007/978-3-642-79868-9_2

[46] Bélanger, F., \& Carter, L. (2008). Trust and risk in e-government adoption. The Journal of Strategic Information Systems, 17(2), 165-176. https://doi.org/10.1016/j.jsis.2007.12.002

[47] Carter, L., \& Bélanger, F. (2005). The utilization of e-government services: citizen trust, innovation and acceptance factors. Information systems journal, 15(1), 5-25. https://doi. org/10.1111/j.1365-2575.2005.00183.x

[48] Bandura, A. (2010). Self-efficacy. The Corsini encyclopedia of psychology, 1-3.

[49] Mensah, I. K., \& Mi, J. (2019). Computer Self-Efficacy and e-Government Service Adoption: The Moderating Role of Age as a Demographic Factor. International Journal of Public Administration, 42(2), 158-167. https://doi.org/10.1080/01900692.2017.1405980 
[50] Almaiah, M., Kanagwa, B., Nasereddin, Y. (2020). Factors Influencing the Adoption of Egovernment Services among Jordanian Citizens. Electronic Government, An International Journal, 16(1). https://doi.org/10.1504/eg.2020.10019265

[51] Sá, F., Rocha, Á., \& Cota, M. P. (2016). From the quality of traditional services to the quality of local e-Government online services: A literature review. Government Information Quarterly, 33(1), 149-160. https://doi.org/10.1016/j.giq.2015.07.004

[52] Safa, N. S., Von Solms, R., \& Futcher, L. (2016). Human aspects of information security in organisations. Computer Fraud \& Security, 2016(2), 15-18. https://doi.org/10.1016/ s1361-3723(16)30017-3

[53] Shareef, M. A., Baabdullah, A., Dutta, S., Kumar, V., \& Dwivedi, Y. K. (2018). Consumer adoption of mobile banking services: An empirical examination of factors according to adoption stages. Journal of Retailing and Consumer Services, 43, 54-67. https://doi.org/10. 1016/j.jretconser.2018.03.003

[54] Rodrigues, G., Sarabdeen, J., \& Balasubramanian, S. (2016). Factors that influence consumer adoption of e-government services in the UAE: A UTAUT model perspective. Journal of Internet Commerce, 15(1), 18-39. https://doi.org/10.1080/15332861.2015.1121460

[55] Muthu, P. P., Thurasamy, R., Alzahrani, A. I., Alfarraj, O., \& Alalwan, N. (2016). E-Government service delivery by a local government agency: The case of E-Licensing. Telematics and informatics, 33(4), 925-935. https://doi.org/10.1016/j.tele.2016.02.003

[56] Alshehri, M., Drew, S., \& AlGhamdi, R. (2013). Analysis of citizens acceptance for e-government services: applying the UTAUT model. arXiv preprint arXiv:1304.3157.

[57] Hair, J. F., Ringle, C. M., \& Sarstedt, M. (2013). Partial least squares structural equation modeling: Rigorous applications, better results and higher acceptance. Long range planning, 46(1-2), 1-12. https://doi.org/10.1016/j.lrp.2013.01.001

[58] Sekaran, U., \& Bougie, R. (2009). Research Methods for Business: John Willey \& Sons Ltd.

[59] Adelson, J. L., \& McCoach, D. B. (2010). Measuring the mathematical attitudes of elementary students: The effects of a 4-point or 5-point Likert-type scale. Educational and Psychological measurement, 70(5), 796-807. https://doi.org/10.1177/0013164410366694

[60] Fornell, C., \& Larcker, D. F. (1981). Structural equation models with unobservable variables and measurement error: Algebra and statistics. https://doi.org/10.2307/3150980

[61] Tabachnick, B. G., \& Fidell, L. S. (2013). Using multivariate statistics, 6th edn Boston.Ma: Pearson.

\section{Authors}

Mohammed Amin Almaiah (Corresponding Author) received his $\mathrm{PhD}$ in Computer Science from University Malaysia Terengganu from Malaysia. MSc in Computer Information System from Middle East University (MEU) in 2011 from Jordan. He is now working as Assistant Professor in the Department of CIS at King Faisal Saudi Arabia. He has published over 15 research papers in highly reputed journals such as the Engineering and Science Technology, an International Journal, Education and Information Technologies, the Journal of Educational Computing Research and others. Most of his publications were indexed under the ISI Web of Science and Scopus. His current research interests include mobile learning, software quality, network security and technology acceptance. He is a certified recognized Reviewer by several leading journals in IEEE, Elsevier and Springer. 
Ahmad Al-Khasawneh is a professor of computer information systems. He holds the $\mathrm{PhD}$ and M.Sc. of information systems and computer engineering from Newcastle University, Australia and B.S in computer and automatic control engineering. Dr. Khasawneh has 25 years of experience in ICT field and in ICT applications and acts as technical advisor to the Royal Jordanian Airlines (NDC Jordan) director on issues related to the development of travel industry and ICT strategy. Prior to joining the Hashemite University of Jordan, he held several key positions with major international ICT consultancy and solutions firms and lecturer in IT related topics at Newcastle University, Australia. One of his key positions is the director of eLearning center and, he is the former dean of the Prince Hussein Bin Abdullah II for Information Technology at Hashemite University. Currently, he is the director of center of information and communication technology and eLearning. He is managing and coordinating three Tempus projects; and four erasmus+ project, and a head and member of the many committees of another Tempus and Erasmus+ project. He is very well-known in the EU project management.

Ahmad Althunibat Associate professor at Department of Software Engineering, Al-Zaytoonah University of Jordan, Amman, Jordan

Saleh Khawatreh Associate professor at Department of Computer Engineering, Al Ahliyya Amman University, Jordan.

Article submitted 2019-07-12. Resubmitted 2019-11-09. Final acceptance 2019-11-13. Final version published as submitted by the authors. 